\title{
Article \\ Evaluation of Selected Thermal Changes in Textile Materials Arising in the Wake of the Impact of Heat Radiation
}

\author{
Waldemar Machnowski ${ }^{1, *(D)}$ and Jolanta Wąs-Gubała ${ }^{2}$ (D) \\ 1 Institute of Material Science of Textiles and Polymer Composites, Lodz University of Technology, \\ Zeromskiego 116, 90-924 Lodz, Poland \\ 2 Institute of Forensic Research, Westerplatte 9, 31-033 Krakow, Poland; jwas@ies.gov.pl \\ * Correspondence: waldemar.machnowski@p.lodz.pl
}

Citation: Machnowski, W.;

Wass-Gubała, J. Evaluation of Selected Thermal Changes in Textile Materials Arising in the Wake of the Impact of Heat Radiation. Appl. Sci. 2021, 11, 6989. https://doi.org/10.3390/ app11156989

Academic Editor: Rocco Furferi

Received: 24 April 2021

Accepted: 28 July 2021

Published: 29 July 2021

Publisher's Note: MDPI stays neutral with regard to jurisdictional claims in published maps and institutional affiliations.

Copyright: (c) 2021 by the authors. Licensee MDPI, Basel, Switzerland. This article is an open access article distributed under the terms and conditions of the Creative Commons Attribution (CC BY) license (https:// creativecommons.org/licenses/by/ $4.0 /)$.
Abstract: The detection of changes in the morphological and chemical structure of four cotton/polyester blend fabrics and their constituent fibres caused by thermal radiation was the purpose of the study. Relatively short exposure times, i.e., $20 \mathrm{~s}, 25 \mathrm{~s}, 30 \mathrm{~s}$ and $40 \mathrm{~s}$, of fabrics for an incident heat flux density of $10 \mathrm{~kW} / \mathrm{m}^{2}$ were applied so that they did not cause changes visible to the naked eye. Such experimental conditions have been selected to resemble the ones that may occur during firefighting, rescue operations, some professional activities as well as during criminal events. The assumption that using the sequence of physicochemical methods, i.e., optical microscopy, scanning electron microscopy and FTIR spectroscopy, will make it possible to identify selected thermal changes in examined materials caused by a short-term temperature increase has been positively verified. Out of applied techniques, scanning electron microscopy showed the highest efficiency in tracking morphological changes in fibres occurring under the influence of heat radiation, while the FTIR method allows for the identification of thermal changes in the chemical structure of cotton fibres. Optical microscopic methods were also characterised by relatively high usefulness in the detection of thermal changes, especially in terms of the physical microstructure of PES fibres. The changes occurring in the fibres due to the action of heat radiation depend not only on the thermal behaviour of a particular type of fibre but also on the structural parameters of the examined textiles, i.e., porosity, and the mutual position of particular types of fibres in the three-dimensional structure of yarns and fabrics. Moreover, the studies revealed the presence of tiny, deformed balls at the ends of the thermoplastic fibres, visible on the surface of some original polyester-cotton textiles, caused by a singeing technological process, which should be taken into account during interpretation of analytical findings.

Keywords: polyester fibres; cotton; fabric blend; thermal behaviour; thermal degradation; FTIR; SEM

\section{Introduction}

Textile materials, including constituent fibres, can be subjected to degradation under the influence of various factors that occur during textile use. Degradation is the process of structural changes as a result of physical or chemical transformation that occurs in polymer materials under the influence of external factors. For textiles, the most common of these factors are light, high temperature, adverse environmental conditions (moisture, microorganisms, UV radiation) and chemicals used in the washing process (detergents, bleaching agents, enzymes, organic solvents) [1].

Thermal degradation of fibre occurs when its chemical properties alter under the influence of high temperature, i.e., there is a change in the molecular structure in the form of the partial depolymerisation or cross-linking of fibre polymer [2,3]. The behaviour of fibres at high temperatures depends on their type. Natural (i.e., cotton, flax, hemp) and man-made (viscose, modal and lyocell) cellulosic fibres react substantially differently than synthetic fibres, e.g., polyesters, when exposed to a heat source. The heating of cellulose 
fibres in the presence of oxygen causes some amount of hydrolysis and dehydration, the extent of which is directly proportional to the temperature $[3,4]$. It should be noted that even a high degree of thermal destruction of cellulosic fibres does not usually cause clearly visible changes in their morphological structure [5,6]. However, synthetic fibres, mainly thermoplastic in nature, become soft at high temperatures. Textiles made of polyester, polyamide or polypropylene fibres shrink and deform when exposed to heat. Subsequently, these fibres tend to melt.

The thermal degradation of cellulose fibres is an important issue in the production processes of plant fibre-reinforced composites as well as in the manufacturing of flame retardant textiles $[7,8]$. In the processes of finishing textile products, in order to achieve the desired aesthetics and performance, dyes and various chemicals are introduced into the structure of the fibres. In addition, as a result of use, textile products can contain various types of pollution. Under high temperatures, many of these substances may also speed up the degradation of fibres $[3,8]$.

An accurate determination of damage to individual fibres in a variety of textile products is very important, both from a scientific and a practical point of view. This is necessary, for example, when assessing the state of preservation of antique fabrics $[9,10]$ or for determining the degree of wear of thermal protective clothing [11,12].

Identification of thermal changes observed in single fibres is very important from the forensic science point of view $[13,14]$. High-temperature effects can be often observed during examination of evidential material in the form of fragments of single fibres, secured, for example, at a crime scene (arson or car accident). By studying single fibres that have changed thermally, one can evaluate their unique characteristics and subsequently relate an individual to a specific criminal event.

The heat not only causes irreversible changes in the morphological and chemical structure of the fibre but is often the cause of its total destruction. The task of the forensic expert examining thermally altered fibres is to define the properties of the textile material before the changes that occurred under the influence of heat [15]. Many modern instrumental analysis methods allow fibres altered in such a way to be examined to some extent. The use of microscopic methods-optical and electron [6,16,17] and FTIR spectroscopy [18-20] — can yield very valuable research results. A new effective tool for non-destructive testing of the internal microstructure of fibres and fibrous materials is a method of X-ray microtomography [21,22].

This publication addresses a part of this broad issue related to the study of thermally altered fibres, i.e., identification of changes caused by the action of heat radiation. The purpose of the research was to determine changes caused by thermal radiation in the morphological and chemical structure of the two most commonly used types of fibres, e.g., cotton and polyester, originating from the fabrics exposed to heat radiation of $10 \mathrm{~kW} / \mathrm{m}^{2}$. Such environmental conditions may occur during firefighting and rescue operations, as well as during other professional activities, e.g., some jobs in the steel industry. Therefore, many researchers investigate the thermal performance of protective clothing and the risk of burns when exposed to heat flux levels in the range between $5 \mathrm{~kW} \cdot \mathrm{m}^{-2}$ and $20 \mathrm{~kW} \cdot \mathrm{m}^{-2}[23,24]$.

Relatively short exposure times of fabric samples were used so as not to cause changes in these samples that would be visible to the naked eye. The assumption that microscopic and spectroscopic analysis of these fabrics will allow for some thermal changes to be identified in fibres even during short-term exposure to heat was adopted. It was also assumed that the use of sequences of these research methods, analogously as implemented in forensic laboratories for identification and comparison of evidential fibres, will bring better results than the use of each method separately.

\section{Materials and Methods}

\subsection{Materials}

The subject of the presented research constituted samples of four textile materials from clothing purchased on the consumer market. The tested fabrics can be regarded as representative examples of apparel fabrics available on the market today. 
The preliminary research focused on textile fibres identification and on confirming the fibre composition of tested textiles with the content of the labels. The thickness and the mass per unit area of the tested fabrics (in accordance with, respectively, EN ISO 5084 [25] and EN 12127 [26]) and their porosity (as described in the article [24]) were also determined. The examined materials differed in terms of product type (woven fabric, knitted fabric), construction and fibre composition. All tested textile products were mixtures of cotton (CO) with polyester (PES) fibres. The basic characteristics of the examined CO/PES blend textiles are given in Table 1.

Table 1. Characteristic of examined textile materials.

\begin{tabular}{cccccc}
\hline Sample Number & $\begin{array}{c}\text { Material } \\
\text { Composition }\end{array}$ & $\begin{array}{c}\text { Mass Per Unit } \\
\text { Area, } \mathbf{g} \cdot \mathbf{m}^{-2}\end{array}$ & $\begin{array}{c}\text { Thickness, } \\
\mathbf{m m}\end{array}$ & Porosity, \% & Other Features of Sample \\
\hline 1 & $\begin{array}{c}83 \% \text { CO, } \\
17 \% \text { PES }\end{array}$ & $260 \pm 5$ & $1.25 \pm 0.15$ & $86 \pm 2$ & $\begin{array}{c}\text { Sweater; knitted fabric with a raised } \\
\text { uncut loops of thread covering its } \\
\text { outer side }\end{array}$ \\
\hline 2 & $\begin{array}{c}79 \% \text { CO, } \\
21 \% \text { PES }\end{array}$ & $356 \pm 7$ & $2.40 \pm 0.26$ & $90 \pm 1$ & $\begin{array}{c}\text { Pants; pile knit with a cut-pile surface } \\
\text { on the outer side }\end{array}$ \\
\hline 3 & $\begin{array}{l}75 \% \text { CO, } \\
25 \% \text { PES }\end{array}$ & $130 \pm 4$ & $0.34 \pm 0.03$ & $74 \pm 2$ & Shirt; woven fabric with a plain weave \\
\hline 4 & $\begin{array}{l}70 \% \text { CO, } \\
30 \% \text { PES }\end{array}$ & $237 \pm 5$ & $0.67 \pm 0.05$ & $76 \pm 2$ & Pants; woven fabric with a twill weave \\
\hline
\end{tabular}

\subsection{Exposure of Fabrics to Heat Radiation}

The tests were performed at a test stand conforming to EN ISO 6942 [27]. Fabric samples with dimensions of approximately $150 \times 200 \mathrm{~mm}$ were fastened to a metal holder and installed in a vertical position. During the experiment, the heat radiation source in the form of six silicon carbide $(\mathrm{SiC})$ heating rods reaches a temperature of about $1100{ }^{\circ} \mathrm{C}$. The heat flux generated by the radiator is directed towards the surface of the fabric sample. The tests were carried out for an incident heat flux density of $10 \mathrm{~kW} \cdot \mathrm{m}^{-2}$. Thermal degradation of textile samples by exposure to heat radiation was performed only to a small extent. The tests were carried out until the first effects of heat visible to the naked eye appeared on the surface of the fabric samples.

The fabric samples were exposed to such heat radiation intensity for $20 \mathrm{~s}, 25 \mathrm{~s}, 30 \mathrm{~s}$ and $40 \mathrm{~s}$.

\subsection{Microscopic Analysis of Fabrics and Fibres}

The analysis of the surface morphology of cotton and polyester fibres in the tested fabrics samples before and after exposure to heat radiation was carried out with the use of high-resolution scanning electron microscopy: the NOVA NANOSEM 230 microscope (FEI, Eindhoven, Netherlands). SEM images of fabrics' surface were obtained at a magnification of $100 \times$ and an accelerating voltage of $3 \mathrm{kV}$ while longitudinal view and cross-section of fibres were recorded with magnifications of $100 \times, 400 \times, 800 \times$ and $1600 \times$ using accelerating voltages of $3 \mathrm{kV}$ or $10 \mathrm{kV}$. All the fabric samples were coated with gold before the SEM observation.

Observations of fibres forming the research material were conducted with the use of bright-field and polarised light microscopy - the Eclipse E600 Pol (Nikon, Tokyo, Japan) microscope, equipped with $10 \times, 20 \times$ and $40 \times$ objective lenses. Images were recorded using a DS-Fi3 high-definition colour microscope camera equipped with a 5.9-megapixel CMOS image sensor (Nikon, Tokyo, Japan). A NIS-Elements AR system (Nikon, Tokyo, Japan) was used for the processing of obtained data. For detailed optical microscopic examination, fibre samples were placed on microscope glass slides (Menzel Glaser, Braunschweig, Germany) with a drop of mounting medium pure glycerine (Merck KGaA, Darmstadt, Germany) and covered with coverslips (Menzel Glaser, Braunschweig, Germany). The shade and the 
depth of dyeing, as well as the fibre morphology, were examined. The principal optical properties of fibres were compared in polarised light.

\subsection{Micro-FTIR Spectroscopy Analysis of Fibres}

The micro-FTIR spectroscopy research was conducted with the use of Nicolet iN10 Infrared Microscope (ThermoFisher Scientific, Waltham, MA, USA), in transmission mode, with a liquid nitrogen-cooled MCT detector. The spectra were recorded in the range $600 \mathrm{~cm}^{-1}-4000 \mathrm{~cm}^{-1}$. The following measuring conditions were applied: number of accumulations, 128; resolution, $4 \mathrm{~cm}^{-1}$. The data obtained during measurements were processed using an OMNIC Spectra Software (ThermoFisher Scientific, Waltham, MA, USA). Five individual fibres of cotton and five polyesters were selected from every examined sample. They were taken from the original textile materials and from the samples subjected to heat radiation for $20 \mathrm{~s}, 25 \mathrm{~s}, 30 \mathrm{~s}$ and $40 \mathrm{~s}$. Then, the fibres were crushed in order to obtain a flat sample area for measurement. The bands characteristic for carbon dioxide were removed from the received spectra.

\section{Results and Discussion}

\subsection{SEM Analysis}

Scanning electron microscopy (SEM) images of untreated textile samples and samples after heat exposure are shown in Figures 1-4. An SEM examination of textiles provided important information on the reaction of both fabrics and single fibres to a rapid rise in temperature. As expected, it was found that the types of thermal changes for thermoplastic polyester fibres and thermoset cotton fibres are clearly different.
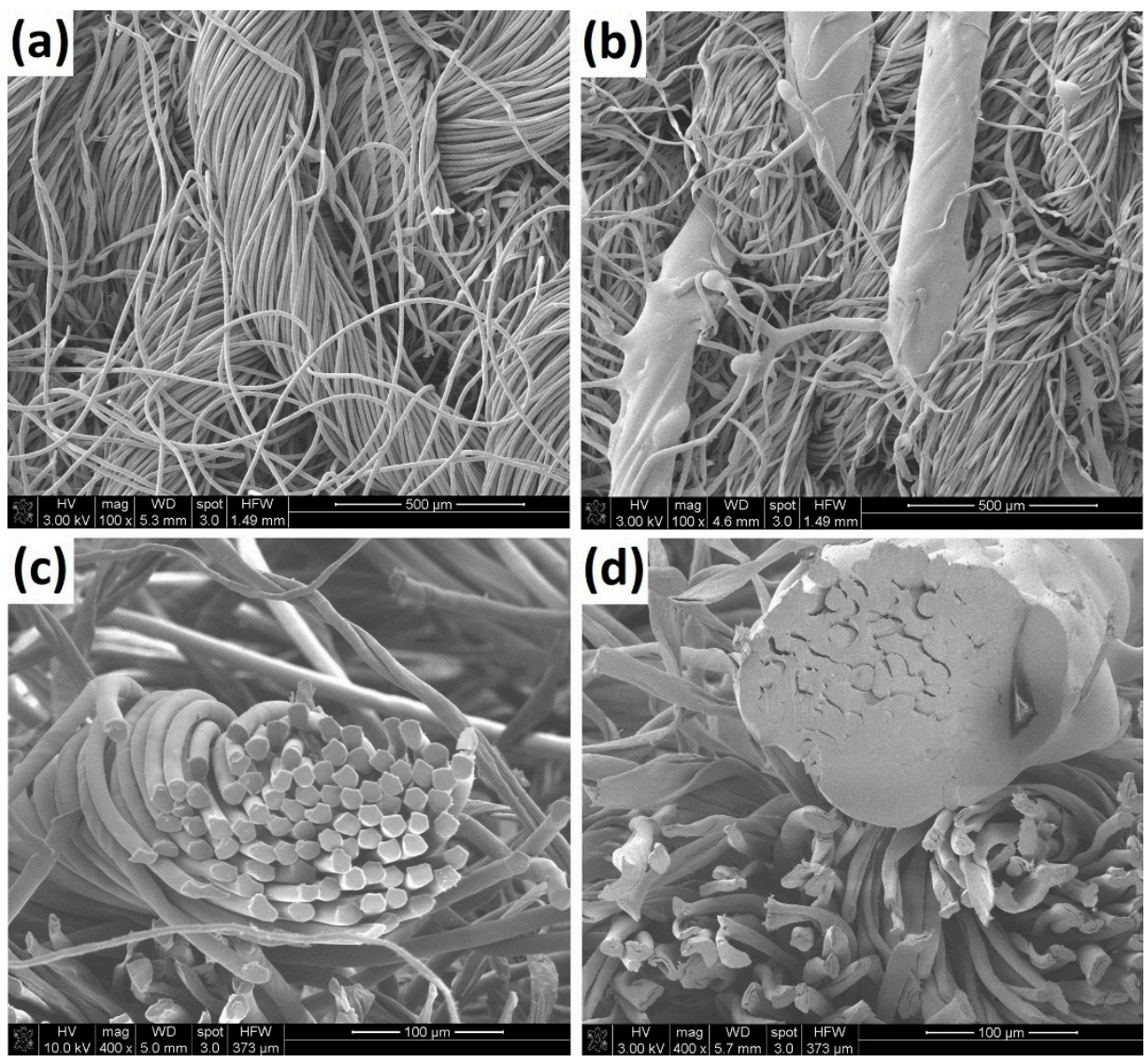

Figure 1. SEM images of Sample 1 (CO 83/PES 17): Knitted fabric surface (magnification 100×) (a) before exposure and (b) after radiant heat exposure $\left(10 \mathrm{~kW} \cdot \mathrm{m}^{-2}, 30 \mathrm{~s}\right)$; cross-section of yarn (magnification $400 \times)\left(\right.$ c) before exposure and $(\mathbf{d})$ after radiant heat exposure $\left(10 \mathrm{~kW} \cdot \mathrm{m}^{-2}, 30 \mathrm{~s}\right)$. 

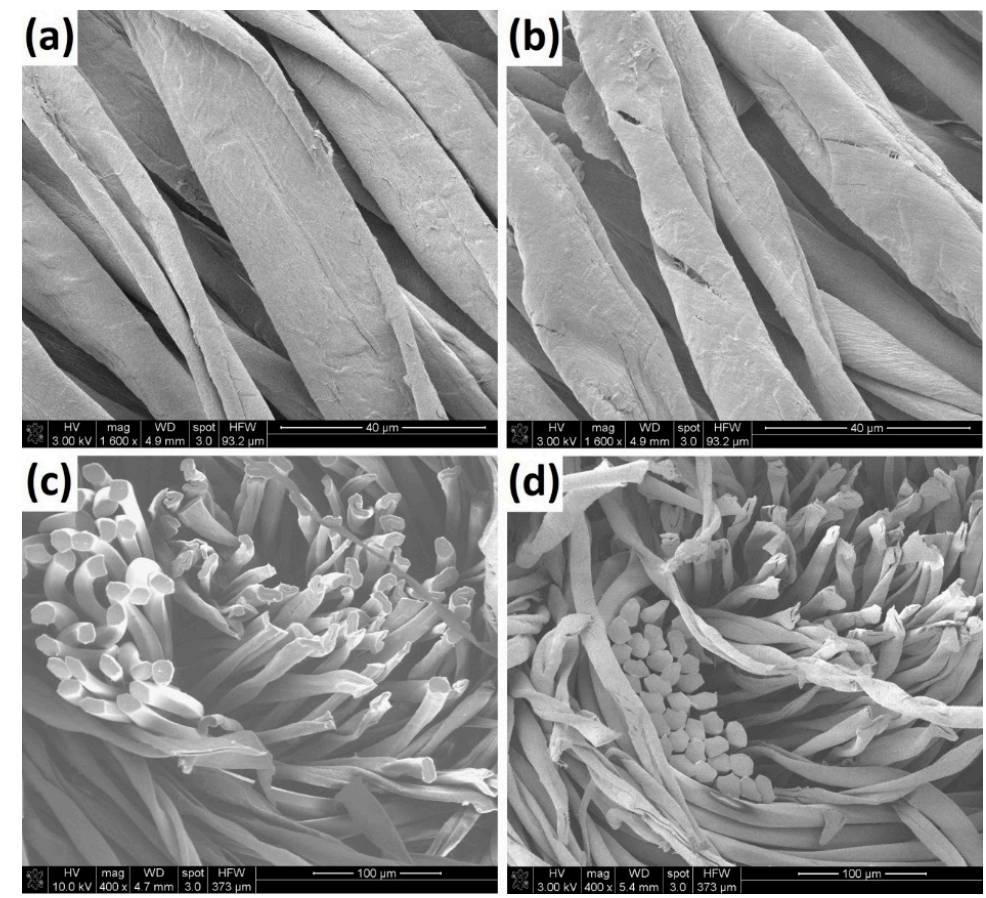

Figure 2. SEM images of Sample 2 (CO 79/PES 21): Cotton fibres surface (magnification $1600 \times$ ) (a) before exposure and (b) after radiant heat exposure $\left(10 \mathrm{~kW} \cdot \mathrm{m}^{-2}, 40 \mathrm{~s}\right)$; cross-section of yarn (magnification $400 \times)\left(\right.$ c) before exposure and (d) after radiant heat exposure $\left(10 \mathrm{~kW} \cdot \mathrm{m}^{-2}, 40 \mathrm{~s}\right)$.


Figure 3. SEM images of Sample 3 (CO 75/PES 25): Woven fabric surface (magnification 100×) (a) before exposure and (b) after radiant heat exposure $\left(10 \mathrm{~kW} \cdot \mathrm{m}^{-2}, 40 \mathrm{~s}\right)$; cross-section of yarn (magnification $800 \times)\left(\right.$ c) before exposure and $(d)$ after radiant heat exposure $\left(10 \mathrm{~kW} \cdot \mathrm{m}^{-2}, 40 \mathrm{~s}\right)$. 

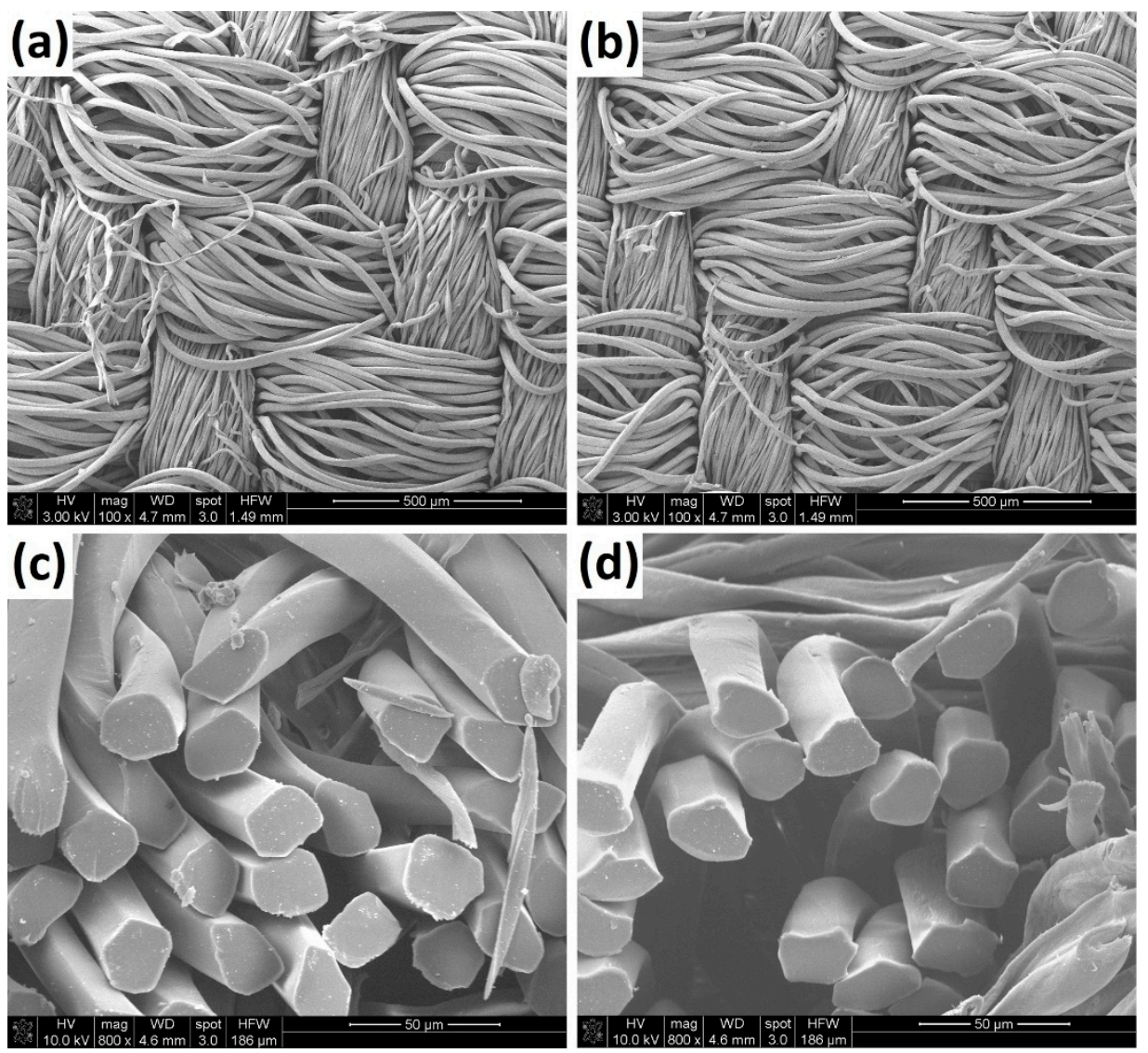

Figure 4. SEM images of Sample 4 (CO 70/PES 30): Woven fabric surface (magnification 100×): (a) before exposure; (b) after radiant heat exposure $\left(10 \mathrm{~kW} \cdot \mathrm{m}^{-2}, 40 \mathrm{~s}\right)$, Cross-section of yarn (magnification $800 \times)$ : (c) before exposure; (d) after radiant heat exposure $\left(10 \mathrm{~kW} \cdot \mathrm{m}^{-2}, 40 \mathrm{~s}\right)$.

\section{Sample 1}

The outer side of the knitted fabric was formed with raised loops of two types of yarn loosely arranged. The first was made of cotton fibres and the second of polyester fibres with a diameter of approximately $13 \mu \mathrm{m}$ (Figure 1a). During a $25 \mathrm{~s}$ exposure of this sample to heat radiation, there were no changes in the morphological structure of either cotton fibres or polyester fibres. However, after a $30 \mathrm{~s}$ action of heat flux action on the knitted fabric sample, fibres melted in many places in the polyester yarn. Figure $1 \mathrm{a}, \mathrm{b}$ compare an unexposed and exposed Sample 1 to radiant heat and illustrate the great effect of heat on the surface morphology of the tested fabric. In the SEM image (Figure 1b), one can observe areas of fused polyester fibres on the fabric surface.

During exposure to heat radiation, as a result of fabric heating, when its surface temperature locally exceeds the melting point of polyester (about $260^{\circ} \mathrm{C}$ ), the PES fibres begin to melt. Then, all of them (about 100 individual fibres in the yarn) fuse with each other and form characteristic artefacts in the shape of irregular cylinders with a length of $1000 \mu \mathrm{m}$ and diameter of about 150-200 $\mu \mathrm{m}$. These thermal changes of PES fibres can be observed more easily on the yarn cross-section (Figure 1d).

It should be assumed that the susceptibility of PES fibres to the occurrence of the described thermal changes resulted from the relatively low thickness of the fibres (diameter of approximately $13 \mu \mathrm{m}$ ) and the loose structure of the top layer of the fabric (porosity of $86 \%$ ). Loosely placed PES yarns heat up intensively during exposure to heat radiation because their real contact area with the elements forming the inner layers of the knitted fabric is small. As a result, PES fibres exposed to heat radiation cannot effectively dissipate the thermal energy by conduction into the inner layers of the fabric. 
Sample 2

The knitted fabric was made of cotton and polyester blended yarn with a high cotton fibre content. As can be observed in Figure 2c,d, the yarn was formed of 30-35 polyester fibres surrounded by numerous cotton fibres. Therefore, the surface layer of Sample 2, which was subjected to heat radiation, was mainly composed of cotton fibres. The polyester fibres in Sample 2 during the $40 \mathrm{~s}$ tests did not melt or show visible deformation because they were not exposed to the direct action of heat radiation, as in Sample 1. This indicates that the cotton fibres proved to be an effective thermal protection for polyester fibres during the experiment lasting $40 \mathrm{~s}$. The cotton fibres in Sample 2, both untreated and exposed to heat radiation (Figure 2a,b), show typical smooth surfaces with characteristic natural grooves.

However, these thermal conditions caused changes in the cotton fibres. As can be seen in Table 1, Sample 2 exhibits a very high level of porosity (90\%). Specifically, the loose structure has an outer side of the fabric (made of cut-pile), which was exposed to heat radiation.

Because of the spatial structure of Sample 2 and its resulting good thermal insulation, the heating rate of fibres on the fabric surface was high. As can be observed in Figure $2 b$, the exposure to radiant heat has had an effect on the cotton fibres' surface morphology. In the SEM image, some clear signs of thermal destruction can be observed in the form of local deep longitudinal cracks in the primary and secondary cell walls of cotton fibres. It should be assumed that these thermal changes in the morphological structure of cotton fibres are also accompanied by changes in the chemical structure of cellulose.

\section{Sample 3}

The woven fabric blend of cotton and polyester fibres was made of cotton yarn (warp) and polyester/cotton yarn (weft). The surface images of the fabric before and after $40 \mathrm{~s}$ of exposure to heat radiation are shown in Figure $3 a, b$. Numerous characteristic distorted small "balls" at the ends of polyester fibres are clearly visible on the surface of fabrics before and after heat radiation. A detailed comparison of these images showed a close similarity in the surface topography of both of these fabric samples. This means that the above-mentioned characteristic thermal changes did not appear on the surface of Sample 3 as a result of the experiment performed.

These specific surface changes have already been caused by technological operation in the fabric manufacturing process. Some cotton fabrics, as well as polyester-cotton blends, are subjected (before dyeing) to a singeing process in which the fabric passes over a gas flame at such a speed that only the protruding fibres are removed, and the main body of the fabric is not damaged by the flame. During this operation, protruding cotton fibres were burned, and the ends of polyester fibres that protruded above the fabric surface were shrunk and melted to form the characteristic small deformed "balls".

Comparison of SEM images of yarn cross-sections before and after exposure to thermal radiation (Figure $3 \mathrm{c}, \mathrm{d}$ ) shows that the $40 \mathrm{~s}$ heating of the fabric did not cause any visible changes in the polyester fibres.

Sample 3 shows clearly less porosity than Sample 1 and Sample 2 (Table 1). It can therefore be assumed that the fibres forming the surface layer of Sample 3, when exposed to heat radiation, are more able to dissipate heat by conduction into the inner layers of the fabric than the fibres in knitted fabrics (Sample 1 and Sample 2). As a result, the temperature of the fibres of Sample 3 subjected to heat radiation is lower than that of Sample 1 and Sample 2.

\section{Sample 4}

The woven fabric was formed of polyester yarn (warp) and cotton yarn (weft). As can be observed in Figure $4 a, b$, these two types of yarn differ significantly from each other. The cotton yarn was thinner and more twisted than the polyester yarn.

The outer side of the fabric was formed mainly from polyester fibres, with a thickness of about $25 \mu \mathrm{m}$. These fibres have a much greater thickness than PES fibres in other fabrics 
tested. They are also thicker than cotton fibres, as can be clearly observed in the surface images of Sample 4 (Figure 4a,b). A comparison of the fabric samples' surface images before and after exposure to thermal radiation shows that during a 40 s experiment, there were no visible changes in the fabric surface topography. SEM analysis also showed that the shape and dimensions of the polyester fibres' cross-section in the sample exposed to heat radiation (Figure $4 \mathrm{~d}$ ) do not differ from those in the control sample (Figure $4 \mathrm{c}$ ). It should be assumed that the thermal stability of PES fibres observed in the case of Sample 4 is due to the high thickness of these fibres and the relatively high density (compactness of the structure) of the woven fabric. Its porosity is $76 \%$ (Table 1). Such a geometrical structure of the fabric sample ensures relatively good contact (better than in the case of samples with higher porosity) between the fibres constituting it, which facilitates heat transfer (conduction phenomenon) through this textile material and, as a result, slower heating up of the fibres exposed to heat radiation.

\subsection{Optical Microscopy Analysis}

The results obtained with the use of optical microscopy have been developed separately for cotton and polyester fibres because these fibres were individually selected from the tested fabric samples.

An observation of microscopic images of cotton fibres taken from fabrics exposed to heat radiation for $20 \mathrm{~s}$ did not reveal any visible changes in the fibre structure. Larger damaged areas were noticed after the application of heat radiation for $30 \mathrm{~s}$ and $40 \mathrm{~s}$. After prolonged exposure to heat radiation, cotton fibres became more fragile and, in consequence, torn and jagged, especially on the ends. Nevertheless, for cotton fibres, long-term and thorough observation was required to detect the previously mentioned changes. The main features were noticed only in polarised light, but they could have been mistaken for naturally occurring blackening within cotton fibres (Figure 5a,b).
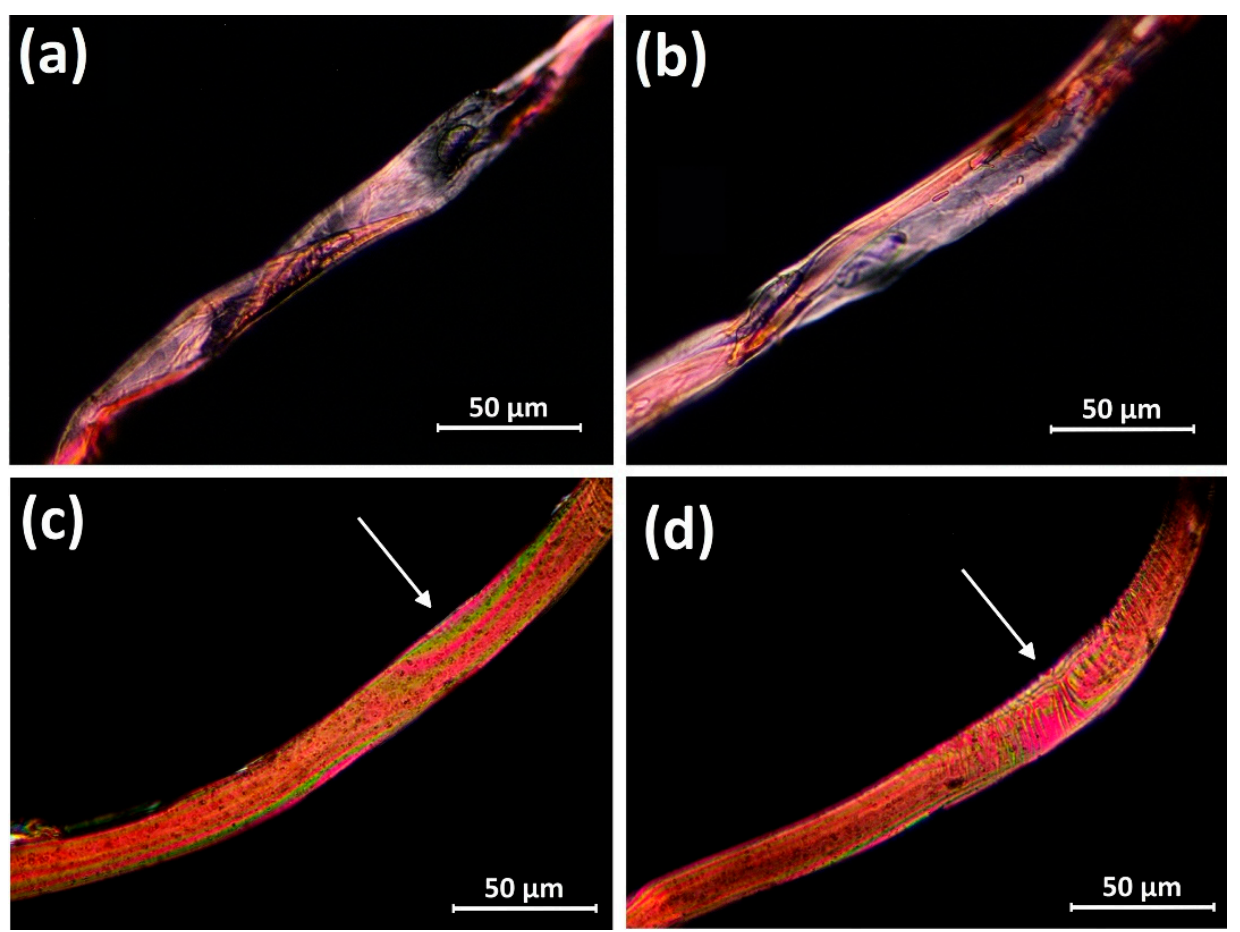

Figure 5. Polarised light microscopy images of cotton fibre of Sample 2 (CO 79/PES 21) and polyester fibre of Sample 4 (CO 70/PES 30): Cotton fibre (a) before exposure and (b) after radiant heat exposure $\left(10 \mathrm{~kW} \cdot \mathrm{m}^{-2}, 40 \mathrm{~s}\right)$; polyester fibre (c) before exposure and $(\mathbf{d})$ after radiant heat exposure $\left(10 \mathrm{~kW} \cdot \mathrm{m}^{-2}\right.$, $40 \mathrm{~s})$. 
The first thermal changes to polyester fibres were visible after an exposure time of $20 \mathrm{~s}$, in the form of small knobs within the fibres with bold on their endings, as well as contractions resulting from melting that were very well outlined in both white and polarised light. Additionally, here and there, narrowings were noticeable in the structure of the fibres; however, the presence of thickened areas connected with melting dominated. The fibres exposed to heat radiation for $30 \mathrm{~s}$ and $40 \mathrm{~s}$ also underwent significant changes in their physical microstructure. The characteristic coloured lines parallel to the fibre axis (Figure 5c) illustrate the overall orientation of the PES fibres before their exposition to heat radiation. The high temperature caused local changes in the fibre physical microstructure, which is reflected in the disturbance of the regular line pattern in the image Figure $5 \mathrm{~d}$ (place indicated by an arrow).

It should be emphasised, however, that in the case of Sample 3, the result of observation was not so obvious because fibres' thickening was observed already in the starting material, indicating a previously applied technological process during which high temperature was used.

\subsection{Micro-FTIR Spectroscopy Analysis}

Literature data were used for the identification of bands in the infrared spectra for both cellulose and polyester fibres [20,28,29]. The polyester fibres in all tested fabric samples were identified as being made from polyethylene terephthalate. In order to adequately interpret the results of further examination, a spectrum of charred cotton fibre was obtained. The shape and position of the absorption bands were not preserved in relation to the spectrum of unchanged cotton, which confirmed the significant impact of high temperature on the chemical structure of the fibre.

An analysis of the infrared spectra obtained for fibres, which were the subject of the experiment, allowed for only minor changes resulting from exposure to radiant heat to be observed as compared to the spectra of the output fibres. On the basis of the obtained results, it was found that they were mainly associated with the shape of the individual bands and the mutual relation of bands' intensities. The most important change observed in the cotton fibres' spectra was the emergence of a new band with a wavenumber of approximately $1580 \mathrm{~cm}^{-1}$ after a $40 \mathrm{~s}$ exposure to heat radiation (Figure 6). The absorption at $1580 \mathrm{~cm}^{-1}$ can be attributed to carbon-carbon double bonds arising from the thermal degradation of cotton cellulose. Other authors also assessed the degree of thermal decomposition of cotton fibres and the char formation based on growing absorptions at $1607-1562 \mathrm{~cm}^{-1}[20]$.

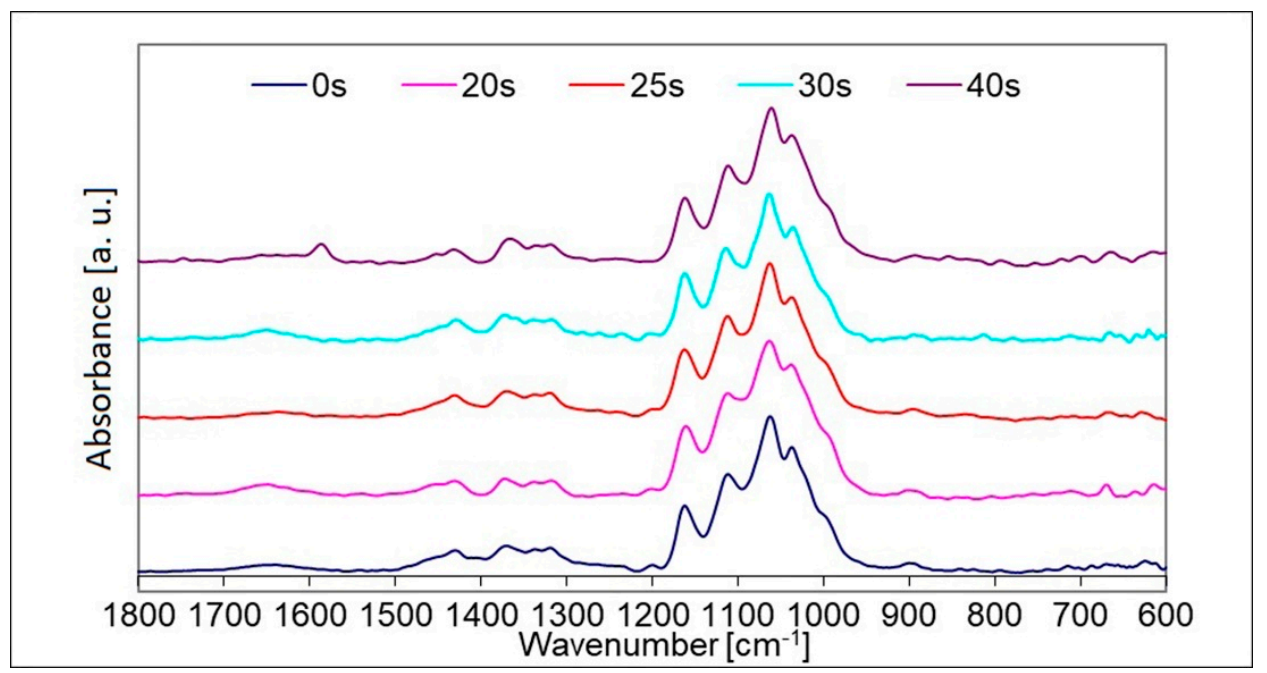

Figure 6. Infrared spectra recorded in the region $600-1800 \mathrm{~cm}^{-1}$ for cotton fibres of Sample 2 (CO $79 /$ PES 21) subjected to heat radiation $\left(10 \mathrm{~kW} / \mathrm{m}^{2}\right)$ for various exposure times. 
The reduction in the intensity of the weak broad band extending from 1620 to $1650 \mathrm{~cm}^{-1}$ provides information on the weakening of the intermolecular hydrogen bonds between the cellulose chains [30]. In other studies, based on a similar spectral range $1619-1641 \mathrm{~cm}^{-1}$, the interaction of the water molecules with the hydrogen bonding network in the cellulose polymer was analysed [31]. In our research, the absorption band in the above-mentioned spectral region for cotton fibres exposed to heat radiation during $40 \mathrm{~s}$ becomes practically invisible (Figure 6), although it was clearly visible for the cotton fibres samples before the thermal test and after exposure to radiation for $15 \mathrm{~s}, 20 \mathrm{~s}$ and $30 \mathrm{~s}$.

An additional change that was noticed in the spectra of cotton fibres after heat flux exposure is the gradual disappearance of the relatively small absorption band at about $1200 \mathrm{~cm}^{-1}$ with increasing exposure time of the sample to heat radiation.

A lack of any significant changes between infrared spectra was noted for original polyester fibres and polyester fibres changed by heat radiation at different exposure times. This means that the thermal conditions during the experiments performed, even though the temperature exceeded the melting point of the PES fibres, did not change the chemical structure of the polyester itself.

\section{Conclusions}

The subject of the research constituted cotton/polyester blend textiles exposed to thermal radiation under controlled conditions that did not cause changes visible to the naked eye in these products. The purpose of the study was to show how thermal changes to this type of material can be revealed under laboratory conditions. In the case of the examination of changes to the single fibres, such an assessment was carried out using methods being applied in forensic laboratories.

The performed investigations show that the changes occurring in the fibres due to the action of heat depend not only on the type of fibres but also on the structural parameters of the textile product. The most essential geometrical parameters of the textiles that determine their thermal resistance in the case of impact of heat radiation are porosity and the mutual positions of particular types of fibres in the three-dimensional structure of yarns and fabrics.

The conducted research has shown that the greater porosity of the textile product, especially the loose, spatial structure of the surface layer, promotes the thermal destruction of the fibres under the influence of heat radiation.

Among the tested textiles, the woven fabrics Sample 3 and Sample 4 (porosity values $74 \%$ and $76 \%$, respectively) showed greater thermal resistance than the knitted fabrics Sample 1 and Sample 2 (porosity values $86 \%$ and 90\%, respectively).

Changes in the morphological structure due to heat appeared in polyester fibres before changes in cotton fibres occurred. Polyester fibres undergo permanent changes in terms of dimensions and shape (shrinkage, deformation, melting). In contrast, cotton fibres, under the influence of heat, changed their chemical structure earlier than PES fibres. This is evidenced by the results of FTIR analysis of cotton and PES fibres.

The assumption that microscopic analysis of textile materials will make it possible to observe and identify some thermal changes in threads and fibres caused even during a short-term temperature increase has been positively verified. The changes observed in the structure of the fibres depended on the thermal properties of fibre polymer; cotton made of thermoreactive polymer (cellulose) underwent more or less extensive charring, while polyester fibres, made of thermoplastic polymer, tended to soften, melt and deform. However, in the examined samples, next to thermally changed fibres, i.e., charred (cotton) or deformed (polyester), fibres with no microscopically observable changes were detected.

The studies also have shown that on the surface of some original cotton textiles containing small amounts of synthetic fibres, the presence of tiny deformed balls at the ends of the thermoplastic fibres can be expected. This is caused by a singeing process of the textile product during manufacture in order to make it smoother and lustrous.

Out of the applied techniques, scanning electron microscopy showed the highest efficiency in tracking morphological changes in fibres occurring under the influence of 
heat radiation. Changes to the shape of whole yarns, particular fibres and their surface were observed. In turn, optical microscopic methods, despite their simplicity and ease of preparation of test samples, were characterised by relatively high usefulness in the identification of thermal changes in textile materials, especially in terms of the physical microstructure of PES fibres.

Changes observed in the FTIR spectrum of cotton fibres derived from Sample 2 (exposure time: $40 \mathrm{~s}$ ) were of a chemical nature, as evidenced by the emergence of a new band. No appearance of new bands or disappearance of the other ones were observed in FTIR spectra of the rest of the examined fibres.

It can be concluded that neither of the instrumental methods used in this work, i.e., FTIR spectroscopy, optical and electron microscopy, was found useful for the complete evaluation of the thermal changes in the morphological and chemical structure of fibres if used on its own. The best approach is to combine all of these methods because each has its own specificity and can provide results that are unattainable by other methods.

The results of the presented research can be useful for assessing the degree of damage to protective clothing after exposing it to a specific level of heat flux. Conditions similar to those used in the experiments may occur during firefighting and rescue operations, as well as during certain professional activities (e.g., in metallurgical plants). Therefore, the results of the presented research can also find some practical applications. These results can also be adapted to forensic science when, in the course of the investigation, it becomes necessary to examine evidence in the form of a textile product affected by heat radiation.

Author Contributions: Conceptualization, W.M. and J.W.-G.; methodology, W.M. and J.W.-G.; formal analysis, W.M. and J.W.-G.; investigation, W.M. and J.W.-G.; writing-original draft preparation, W.M. and J.W.-G.; writing-review and editing, W.M. and J.W.-G.; visualization, W.M. and J.W.-G. All authors have read and agreed to the published version of the manuscript.

Funding: This work was partially supported by the statutory research fund of the Institute of Material Science of Textiles and Polymer Composites, Lodz University of Technology, Poland, no. I42/501/4-42-1-1.

Institutional Review Board Statement: Not applicable.

Informed Consent Statement: Not applicable.

Data Availability Statement: The authors can make available data supporting reported results on request.

Acknowledgments: We would like to express our gratitude to Henryk Wrzosek for his SEM analysis of fabrics samples. Justyna Stępien, a graduate of the Chemistry Department of the Jagiellonian University in Kraków, is gratefully acknowledged for her input in achieving the FTIR experimental results.

Conflicts of Interest: The authors declare no conflict of interest.

\section{References}

1. Azwa, Z.N.; Yousif, B.F.; Manalo, A.C.; Karunasena, W. A review on the degradability of polymeric composites based on natural fibres. Mater. Des. 2013, 47, 424-442. [CrossRef]

2. Shalaby, S.W. Thermal Characterization of Polymeric Materials; Academic Press: Orlando, FL, USA, 1981.

3. Nguyen, T.M.; Chang, S.; Condon, B.; Thomas, T.; Azadi, P. Thermal decomposition reactions of cotton fabric treated with piperazine-phosphonates derivatives as a flame retardant. J. Anal. Appl. Pyrolysis 2014, 110, 122-129. [CrossRef]

4. Cai, Z.; Ji, B.; Yan, K.; Zhu, Q. Investigation on Reaction Sequence and Group Site of Citric Acid with Cellulose Characterized by FTIR in Combination with Two-Dimensional Correlation Spectroscopy. Polymers 2019, 11, 2071. [CrossRef] [PubMed]

5. Machnowski, W.; Wrzosek, H. Changes in some properties of flame resistant textiles during their use. In Innovative Technical Textiles; Masajtis, J., Ed.; Monography of Lodz University of Technology: Lodz, Poland, 2016.

6. Barbalini, M.; Bertolla, L.; Toušek, J.; Malucelli, G. Hybrid Silica-Phytic Acid Coatings: Effect on the Thermal Stability and Flame Retardancy of Cotton. Polymers 2019, 11, 1664. [CrossRef] [PubMed]

7. Liang, S.; Nouri, H.; Lafranche, E. Thermo-compression forming of flax fibre-reinforced polyamide 6 composites: Influence of the fibre thermal degradation on mechanical properties. J. Mater. Sci. 2015, 50, 7660-7672. [CrossRef] 
8. Xu, D.; Ji, Q.; Tan, L.; Tian, G.; Quan, F.; Xia, Y. Influence of Alkaline Metal Ions on Flame Retardancy and Thermal Degradation of Cellulose Fibers. Fibers Polym. 2014, 15, 220-225. [CrossRef]

9. Kavkler, K.; Gunde-Cimerman, N.; Zalar, P.; Demšar, A. FTIR spectroscopy of biodegraded historical textiles. Polym. Degrad. Stab. 2011, 96, 574-580. [CrossRef]

10. Gutarowska, B.; Pietrzak, K.; Machnowski, W.; Milczarek, J. Historical textiles-A review of microbial deterioration analysis and disinfection methods. Text. Res. J. 2017, 87, 2388-2406. [CrossRef]

11. Rossi, R.M. Performance of Firefighters' Protective Clothing After Heat Exposure. Int. J. Occup. Saf. Ergon. 2008, 14, 55-60. [CrossRef]

12. Cui, Z.; Ma, C.; Lv, N. Effects of Heat Treatment on the Mechanical and Thermal Performance of Fabric Used in Firefighter Protective Clothing. Fibres Text. East. Eur. 2015, 23, 74-78.

13. Wass-Gubała, J.; Krauß, W. Textile damage caused by vapour cloud explosions. Sci. Justice 2004, 44, 209-215. [CrossRef]

14. Schotman, T.G.; Samlal-Soedhoe, R.S.; Van der Weerd, J. Toward a systematic classification of textile damages. Forensic Sci. Rev. 2018, 30, 51-75.

15. Was-Gubala, J.; Krauß, W. Damage caused to fibres by the action of two types of heat. Forensic Sci. Int. 2006, 159, 119-126. [CrossRef]

16. Hearle, J.W.S.; Lomas, B.; Cooke, W.D. Atlas of Fibre Fracture and Damage to Textiles; CRC Press: Boca Raton, FL, USA, 1998.

17. Brozek-Mucha, Z.; Was-Gubala, J. Microscopic and microanalytical examinations of metallic particles and single textile fibers for forensic purposes. In Microscopy Book; Series Number 5, Volume 2, 1480-1491; Formatex Research Center: Badajoz, Spain, 2012.

18. Bilkova, L. Application of infrared spectroscopy and thermal analysis to the examination of the degradation of cotton fibers. Polym. Degrad. Stab. 2012, 97, 35-39. [CrossRef]

19. Yilma, B.B.; Luebben, J.F.; Nalankilli, G. The Effect of Air, Ar and $\mathrm{O}_{2}$ Plasmas on the Electrical Resistivity and Hand-Feel Properties of Polyester/Cotton Blend Fabric. Fibers 2020, 8, 17. [CrossRef]

20. Soares, S.; Camino, G.; Levchik, S. Effect of metal carboxylates on the thermal decomposition of cellulose. Polym. Degrad. Stab. 1998, 62, 25-31. [CrossRef]

21. Puszkarz, A.K.; Wojciechowski, J.; Krucińska, I. Analysis of the thermal insulation of textiles using thermography and CFD simulation based on micro-CT models. Autex Res. J. 2020, 20, 344-351. [CrossRef]

22. Barburski, M.; Straumit, I.; Zhang, X.; Wevers, M.; Lomov, S.V. Micro-CT analysis of internal structure of sheared textile composite reinforcement. Appl. Sci. Manuf. 2015, 73, 45-54. [CrossRef]

23. Song, G.; Gholamreza, F.; Cao, W. Analyzing thermal stored energy and effect on protective performance. Text. Res. J. 2011, 81 1124-1138. [CrossRef]

24. Puszkarz, A.K.; Machnowski, W.; Błasińska, A. Modeling of thermal performance of multilayer protective clothing exposed to radiant heat. Heat Mass Transf. 2020, 56, 1767-1775. [CrossRef]

25. ISO 5084:1996 Textiles-Determination of Thickness of Textiles and Textile Products; ISO: Geneva, Switzerland, 1996.

26. EN 12127:1997 Textiles Fabrics-Determination of Mass per Unit Area Using Small Samples; CEN: Brussels, Belgium, 1997.

27. ISO 6942:2002 Protective Clothing_Protection Against Heat and Fire-Method of Test: Evaluation of Materials and Material Assemblies When Exposed to a Source of Radiant Heat; ISO: Geneva, Switzerland, 2002.

28. Dechant, J. Ultrarotspektroskopische Untersuchungen an Polymeren; Akademie Verlag: Berlin, Germany, 1972.

29. Flincec Grgac, S.; Tarbuk, A.; Dekanic, T.; Sujka, W.; Draczynski, Z. The Chitosan Implementation into Cotton and Polyester/Cotton Blend Fabrics. Materials 2020, 13, 1616. [CrossRef] [PubMed]

30. Zghari, B.; Hajji, L.; Boukir, A. Effect of Moist and Dry Heat Weathering Conditions on Cellulose Degradation of Historical Manuscripts exposed to Accelerated Ageing: 13C NMR and FTIR Spectroscopy as a non-Invasive Monitoring Approach. J. Mater. Environ. Sci. 2018, 9, 641-654.

31. Cintrón, M.S.; Hinchliffe, D.J. FT-IR Examination of the Development of Secondary Cell Wall in Cotton Fibers. Fibers 2015, 3, 30-40. [CrossRef] 